\title{
Corrosion of Steel Embedded in Fly Ash Mortar Using a Transmission Line Model
}

\author{
S. Fajardo, ${ }^{\mathrm{a}, \mathrm{z}}$ A. Sánchez-Deza, ${ }^{\mathrm{a}}$ M. Criado, ${ }^{\mathrm{a}}$ A. La Iglesia, ${ }^{\mathrm{b}}$ and J. M. Bastidas ${ }^{\mathrm{a}, *}$ \\ ${ }^{a}$ National Center for Metallurgical Research (CENIM), CSIC, 28040 Madrid, Spain \\ ${ }^{b}$ Institute of Geosciences (IGEO), CSIC, UCM, 28040 Madrid, Spain
}

\begin{abstract}
Electrochemical impedance spectroscopy was used to study the corrosion behavior of reinforcing steel embedded in alkaline activated fly ash mortar with chloride pollution. The porous nature of the rust layer was studied using a transmission line model and the parameters of the interfacial oxide/hydroxide film were determined by interpretation of the impedance data using a cylindrical pore. The rust layer generated on the steel surface was studied at the end of the experiment (two years) using scanning electron microscopy and X-ray diffraction.

(C) 2014 The Electrochemical Society. [DOI: 10.1149/2.019408jes] All rights reserved.
\end{abstract}

Manuscript submitted January 29, 2014; revised manuscript received April 16, 2014. Published May 3, 2014. This paper is part of the JES Focus Issue on Mathematical Modeling of Electrochemical Systems at Multiple Scales.

Steel embedded in concrete is passivated by the formation of a thin oxide layer on its surface, which is maintained due to the alkaline nature $(\mathrm{pH}>12)$ of the concrete framework pore solution. ${ }^{1}$ Corrosion initiation in reinforced concrete structures (RCS) may occur when the alkalinity is neutralized by carbonation due to the penetration of carbon dioxide in the concrete or by the presence of high concentrations of aggressive ions, mainly chlorides, that penetrate through the pores of the concrete cover, causing local destruction of the passive layer. The result of corrosion is spalling and delamination of the concrete cover owing to the expansive forces imposed by the generation of steel corrosion products, which occupy a greater volume than the steel itself. A corrosion penetration of only $10 \mu \mathrm{m}$ may be sufficient to cause durability issues. ${ }^{2}$ It should be mentioned that the steel thickness loss is not the same as the corrosion product thickness, because depending on the level of oxidation the volume of iron oxides may be up to about 6.5 times the original iron volume. ${ }^{3}$ The deterioration of RCS is often discussed in terms of the so-called Tuutti model, ${ }^{4}$ where the degree of deterioration of reinforced concrete is described as a function of time.

The corrosion of steel reinforcements involves the conversion of iron to oxides and hydroxides in the presence of water and oxygen. Suda et al. studied the chloride-induced corrosion products on carbon steel reinforcements in concrete exposed for 5 years to a marine environment, detecting magnetite $\left(\mathrm{Fe}_{3} \mathrm{O}_{4}\right)$, goethite $(\alpha-\mathrm{FeOOH})$, and lepidocrocite $(\gamma-\mathrm{FeOOH}) .{ }^{5}$ Other researchers have reported that corrosion products may diffuse into the aggregate/paste interface in concrete, finding magnetite adjacent to the aggregate and hematite $\left(\alpha-\mathrm{Fe}_{2} \mathrm{O}_{3}\right)$ close to the cement paste. ${ }^{6-11}$ Duffó et al. characterized the corrosion products on steel embedded in concrete in 65 year-old specimens exposed to the atmospheric environment, identifying magnetite close to the rebar and a mix of goethite and calcite $\left(\mathrm{CaCO}_{3}\right)$ in the external area. ${ }^{12}$ A study of long-term corrosion resistance of metallic reinforcements in concrete was carried out by Chitty et al., ${ }^{13}$ who reported that the steel/binder interface presented a similar pattern for all the studied sites: metallic substrate, dense product layer, transformed medium, and binder. The dense product layer consisted mainly of goethite with magnetite and/or maghemite $\left(\gamma-\mathrm{Fe}_{2} \mathrm{O}_{3}\right)$ marbling.

The need to extend concrete durability has led to the use of different admixtures and modifications to the concrete composition. ${ }^{14,15}$ In this respect, the most promising emerging approach is based on new raw materials suitable for alkaline activation, essentially fly ash (FA) and slag, which give rise to new binding materials generally known as alkaline cements. ${ }^{16}$ Presumably, given their high alkalinity (even higher than ordinary Portland cement (OPC) mortar) and their position on the Pourbaix diagram, activated FA mortars and concretes should passivate steel reinforcements, thus improving the durability

*Electrochemical Society Active Member.

${ }^{\mathrm{z}}$ E-mail: s.fajardo@cenim.csic.es of RCS constructed using these new materials. The alkali activation of type F fly ash (AAFA) is achieved by mixing FA with a highly alkaline solution $(\mathrm{pH}>13)$ and curing the resulting paste to produce a solid material. The main reaction product of AAFA is a sodium aluminosilicate hydrate $(\mathrm{N}-\mathrm{A}-\mathrm{S}-\mathrm{H})$ gel. ${ }^{17,18}$ The capacity to passivate steel and to conserve the passive state once it is reached are dependent on the nature and dosage of the binder, the type of activators, and on environmental factors. ${ }^{19}$ Unfortunately, only very limited information is available on the characterization of corrosion products in reinforced FA mortar. ${ }^{20}$

It is known that on rough and porous electrodes, coplanar electrodes, electrodes of a larger area than the counter electrode, and in general in crevice corrosion processes, the distribution of alternating current $(a c)$ on the electrode is non-uniform. This phenomenon has encouraged a study of the electrical response of porous rust generated on a steel rebar embedded in AAFA mortar using the electrochemical impedance spectroscopy (EIS) method. In the light of the information obtained, this work presents a quantitative analysis of the equivalent circuit elements to describe the evolution of steel damage as a function of time and to elucidate the interfacial characteristics of the AAFA mortar/pore electrode/carbon steel system.

\section{Experimental}

Concrete reinforcement electrodes were cut from carbon steel plates with a chemical composition of $0.45 \% \mathrm{C}, 0.22 \% \mathrm{Si}, 0.72 \%$ $\mathrm{Mn},<0.010 \% \mathrm{P}, 0.022 \% \mathrm{~S}, 0.13 \% \mathrm{Cr}, 0.13 \% \mathrm{Ni}, 0.18 \% \mathrm{Cu}$, and balance $\mathrm{Fe}$. The specimen surfaces were ground with silicon carbide (SiC) emery paper down to grade 600 , washed with double distilled water and degreased with acetone.

The cementitious material used was FA (type F) from a coal-fired power plant at Aboño, Asturias (Spain). The chemical composition of the FA is shown in Table I. The percentage of reactive silica $\left(\mathrm{SiO}_{2}\right)$ in the FA, determined according to UNE 80-225-93 standard, ${ }^{21}$ was $41.23 \%$ and the vitreous phase content was $65.60 \%$. The procedure used to determine the vitreous phase content was similar to that described elsewhere. ${ }^{22}$ Briefly, $1 \mathrm{~g}$ of FA was added to $100 \mathrm{~mL}$ of $1 \%$ hydrofluoric acid (HF) in a plastic beaker and stirred for $6 \mathrm{~h}$ at room temperature. The granulometry distribution, determined by laser ray diffraction, showed only one mode in which approximately $85 \%$ of particles were smaller than $45 \mu \mathrm{m}$ and $50 \%$ smaller than $13 \mu \mathrm{m}$. The FA was activated using an $8 \mathrm{M}$ sodium hydroxide $(\mathrm{NaOH})$ solution $(\mathrm{pH}$ $=13.9)$ with a sodium oxide $\left(\mathrm{Na}_{2} \mathrm{O}\right)$ content of $\sim 20 \%$. The products used to prepare the solution were laboratory grade reagents.

AAFA mortar was manufactured using a $\mathrm{NaOH}$ solution with a liquid/solid ratio of 0.45 . The aggregate:AAFA ratio used to manufacture the mortar was $2: 1$. A standardized, evenly graded siliceous sand was employed $\left(99 \% \mathrm{SiO}_{2}\right.$ content, where $66 \%$ of particles are size 
Table I. Chemical composition of the tested fly ash (\% in mass).

\begin{tabular}{llllllllllllll}
$\mathrm{SiO}_{2}$ & $\mathrm{Al}_{2} \mathrm{O}_{3}$ & $\mathrm{Fe}_{2} \mathrm{O}_{3}$ & $\mathrm{CaO}$ & $\mathrm{MgO}$ & $\mathrm{SO}_{3}$ & $\mathrm{Na}_{2} \mathrm{O}$ & $\mathrm{K}_{2} \mathrm{O}$ & $\mathrm{MnO}$ & $\mathrm{P}_{2} \mathrm{O}_{5}$ & $\mathrm{TiO}$ & LOI & Others & Total \\
\hline 51.78 & 27.80 & 6.18 & 4.59 & 1.52 & 0.71 & 0.59 & 2.51 & 0.06 & 0.62 & 1.35 & 2.23 & 0.06 & 100
\end{tabular}

$<1 \mathrm{~mm}$ and $35 \%<0.5 \mathrm{~mm}$ ). The molds containing the fresh AAFA mortars were subsequently cured in an oven at $85^{\circ} \mathrm{C}$ in a saturated water vapor atmosphere for $20 \mathrm{~h}$. Sodium chloride $(\mathrm{NaCl} ; 99 \%$ pure Panreac PRS-CODEX): $2 \%$ (in relation to binder weight) was added to the FA, which was subsequently mixed with the alkaline solution. Two prism-shaped mortar specimens were prepared for comparative purposes. All the specimens were stored at room temperature in an atmosphere of high relative humidity, approximately $95 \%$, for up to 730 days.

Experiments were performed on small prismatic specimens measuring $8 \times 5.5 \times 2 \mathrm{~cm}^{3}$, (length $\times$ width $\times$ thickness) similar to those used in a previous study. ${ }^{23}$ Two 6-mm wide carbon steel plates, symmetrically embedded in the prisms, were used as working electrodes during the measurements (to account for reproducibility), with an external stainless steel (SS) cylinder of $5 \mathrm{~cm}$ diameter acting as a counter electrode provided with a central hole to insert a saturated calomel electrode (SCE) as reference electrode. A pad soaked in water was used to enable electrical conductivity measurements. An active surface area of $5.6 \mathrm{~cm}^{2}$ was marked on the working electrodes with adhesive tape, thus isolating the triple mortar/steel/atmosphere interface to avoid possible localized corrosion attack due to differential aeration. A schematic representation of the system is presented in Fig. 1.

Steel corrosion over time was monitored using the EIS method. An EG\&G Parc Potentiostat model 273A and a Solartron 1250 Frequency Response Analyzer were utilized for EIS measurements. These were recorded at the corrosion potential $\left(E_{\text {corr }}\right)$ in a frequency range from $64 \times 10^{3} \mathrm{~Hz}$ to $1 \times 10^{-3} \mathrm{~Hz}$ with a logarithmic sweeping frequency of five points per decade. The EIS method involved the imposition of a $10 \mathrm{mV}$ r.m.s. amplitude excitation voltage. $E_{\text {corr }}$ was measured prior to every EIS test.

The simulation of EIS results using the transmission line model (TLM) was performed on MATLAB (Matrix Laboratory) software, while fitting of the other spectra was performed with ZView software.

The rust layer formed on the samples after 730 days' experimentation was examined using a JEOL JSM-6400 scanning electron microscope (SEM) equipped with a Link Systems energy-dispersive $\mathrm{X}$-ray (EDX) microanalyzer (accelerating voltage $15 \mathrm{kV}$, beam current $3 \mathrm{nA}$ ) operating in secondary electron and backscattered electron modes. Crystalline phases present in the specimens were characterized by X-ray diffraction (XRD) using a Bruker D8 Advance diffractometer with a Sol-X detector. X-ray patterns were recorded from 5 to 65

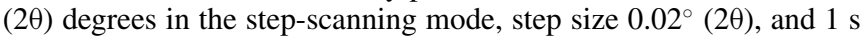
counting time.

\section{Results and Discussion}

Fig. 2 shows the evolution of the $E_{\text {corr }}$ versus time for carbon steel embedded in AAFA mortar polluted with $2 \% \mathrm{NaCl}$. It is possible to observe an exponential decay of the $E_{\text {corr }}$ (see the inset in Fig. 2) and its stabilization at less noble potential values, as observed by the plateau at approximately $-0.650 \mathrm{~V}$ vs. SCE. The decrease in the $E_{\text {corr }}$ exhibited is consistent with an activation of the AAFA mortar/steel interface. ${ }^{20}$ It is observed that even in the early stages of experimentation the steel experiences corrosion, most likely due to the presence of chlorides in the mortar paste, leading to the observed decrease in the $E_{\text {corr }}$. It is worth noting that even under the highly alkaline conditions that the activated fly ash provides to the mortar environment, the presence of chloride ions impedes the formation of a protective oxide layer on the steel electrode surface. The evolution of $E_{\text {corr }}$ over time indicates that steel under the experimental conditions reached a stable active dissolution state after ca. 350 days of experimentation.
Fig. 3 shows the Nyquist plots for steel embedded in AAFA mortar polluted with $2 \% \mathrm{NaCl}$ at different experimentation times. At the beginning of the experiment, for 7,15 , and 30 days of exposure, the Nyquist plots define a capacitive behavior with one time constant, drawing a depressed semicircle which is better defined as the time increases, probably associated with a loss of homogeneity of the surface as a consequence of activation of the steel rebar. From 60 to 730 days the Nyquist plots change to define more than one time constant. It should be noted that as the time increases, the Nyquist plots define a region of near $45^{\circ}$ slope at low frequency values in the complex plane plot, which is a characteristic signature of a porous electrode. ${ }^{24}$

At the end of the experiment (730 days) the samples were broken open and the steel rebar withdrawn and analyzed using the SEM and XRD methods. Fig. 4 shows a SEM micrograph of a carbon steel rebar sample after 730 days' experimentation revealing a conglomerate of laminar particles with a crystalline appearance and a size of more than $50 \mu \mathrm{m}$. It can be observed that the corrosion products generated are of a very porous nature. XRD results indicate that this rust layer contains low percentages of crystalline components, less than $30 \%$, of

a)
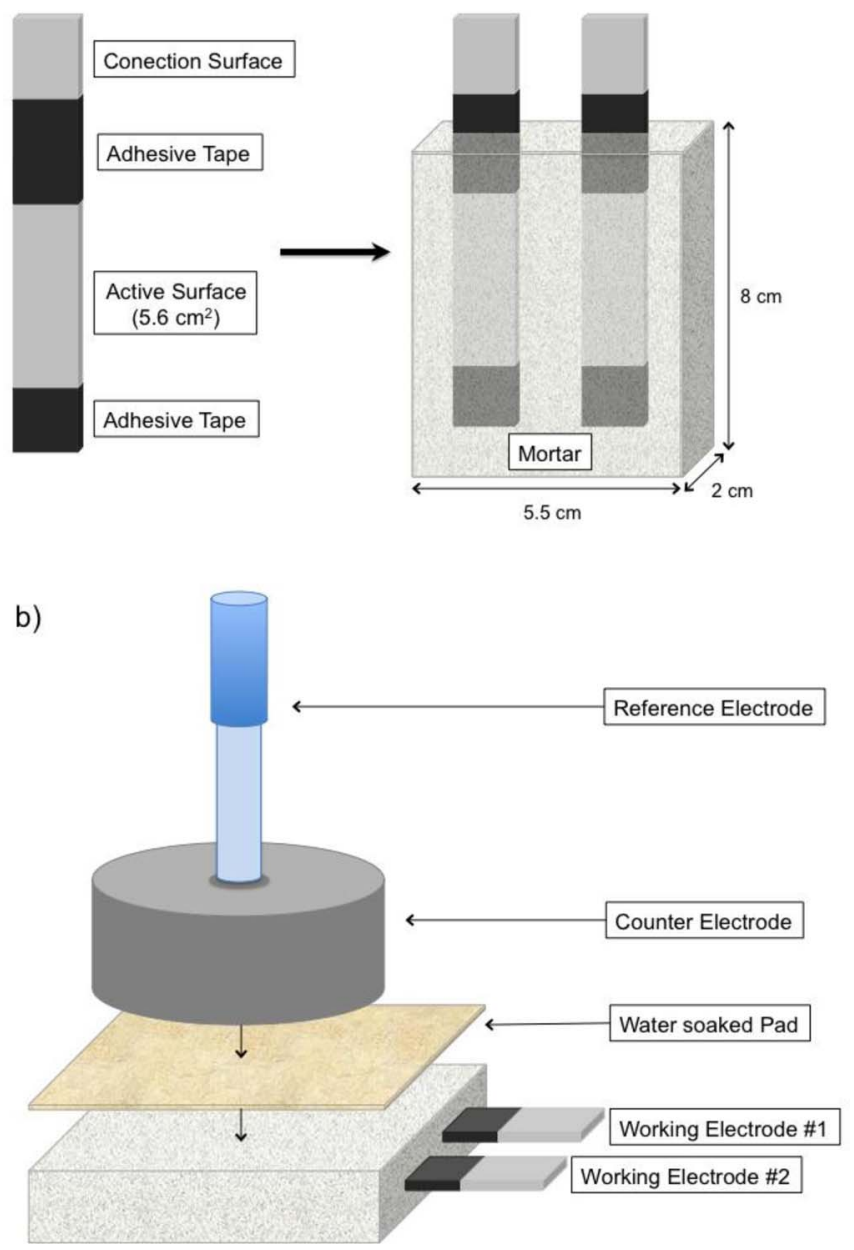

Figure 1. Schematic representation of (a) the electrode preparation and the mortar specimen dimensions; and (b) configuration of the system for the electrochemical measurements. 


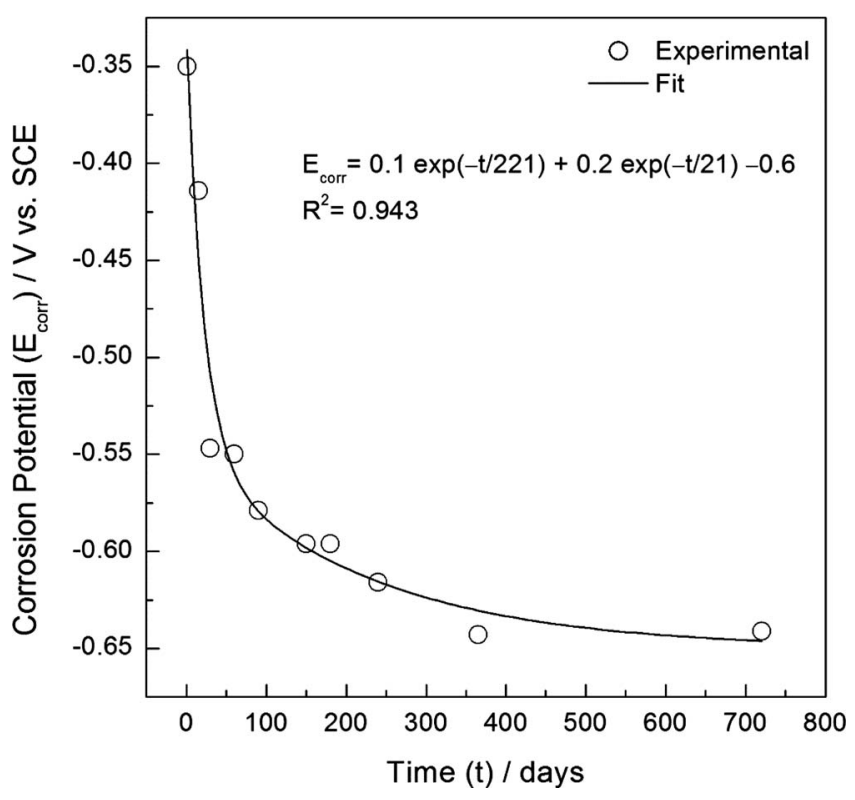

Figure 2. Evolution of the corrosion potential $\left(E_{\text {corr }}\right)$ with time $(\mathrm{t})$ for carbon steel embedded in alkaline activated fly ash mortar polluted with $2 \% \mathrm{NaCl}$ and stored at room temperature in an atmosphere of high relative humidity $(\sim 95 \%)$.

which the majority are of an amorphous nature. XRD patterns show a wide band between 18 and $45^{\circ} 2 \theta$ (radiation $\mathrm{CuK} \alpha$ ) without clear peaks of magnetite, goethite or lepidocrocite. The atomic Fe/O ratio was between 0.41 and 1.00 .

Fig. 5 shows tubular protuberances similar to bubbles with geodelike structures yielded on the carbon steel surface. The diameter of these tubular structures is between 40 and $100 \mu \mathrm{m}$ and they are partially filled with laminar particles of a small size $(10-20 \mu \mathrm{m})$ and a more crystalline appearance than the external wall. The atomic $\mathrm{Fe} / \mathrm{O}$ ratio is $0.39-0.84$ for the external wall and $0.70-1.00$ for the laminar particle filling. As a working hypothesis it is suggested that the tubular structure may contribute to the sodium aluminosilicate hydrate $(\mathrm{N}-\mathrm{A}-\mathrm{S}-\mathrm{H}$ ) gel pore network (in a similar way to the $\mathrm{C}-\mathrm{S}-\mathrm{H}$ gel in ordinary Portland cement, according to the Feldman-Sereda model) as a pathway for the chloride-polluted pore electrolyte to reach the base steel surface.

Fig. 6 shows the Nyquist plots for steel embedded in AAFA mortar polluted with $2 \% \mathrm{NaCl}$ for 7,15 , and 30 days of experimentation. EIS data was simulated using the electrical equivalent circuit (EEC) depicted in the figure, formed by a constant phase element (CPE) in parallel combination with the polarization resistance $\left(R_{\mathrm{p}}\right)$,

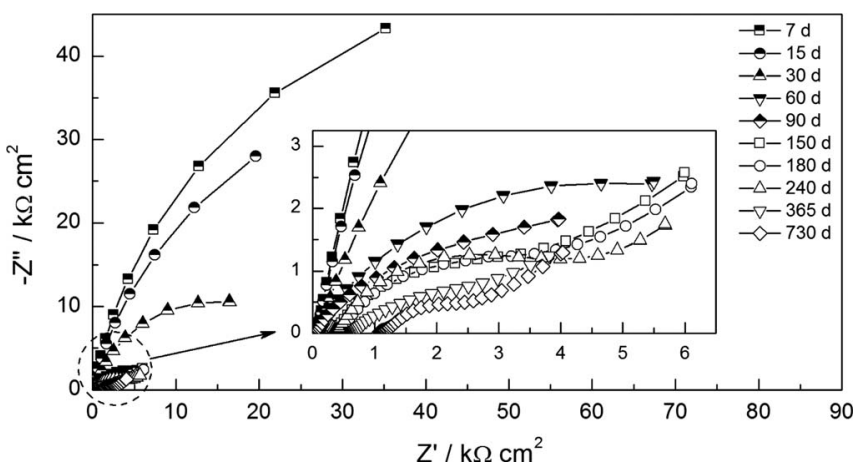

Figure 3. Nyquist plots for carbon steel embedded in alkaline activated fly ash mortar polluted with $2 \% \mathrm{NaCl}$ and stored at room temperature in an atmosphere of high relative humidity $(\sim 95 \%)$.

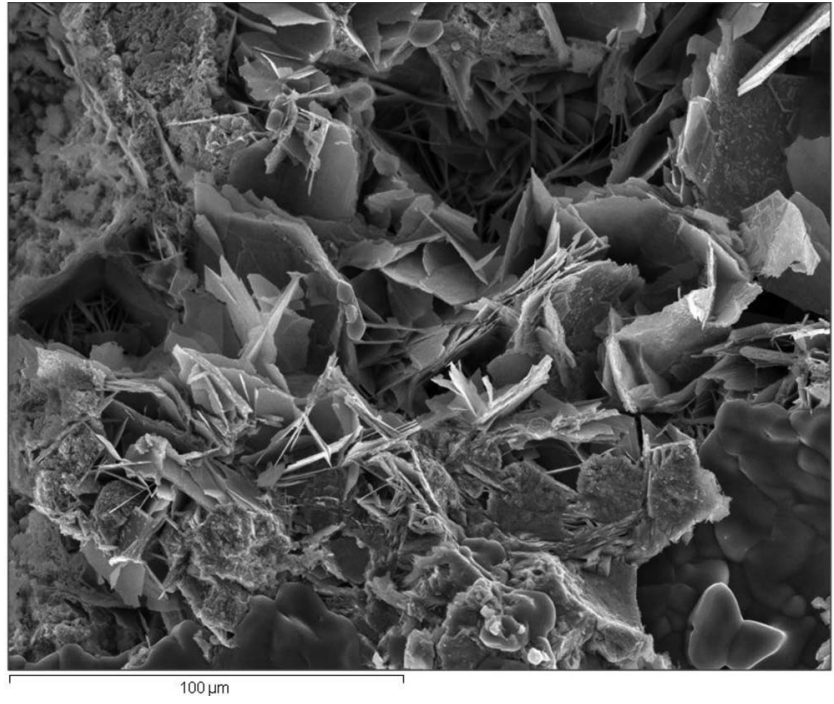

Figure 4. SEM image of carbon steel corrosion products generated at the steel/mortar interface in alkaline activated fly ash mortar polluted with $2 \%$ $\mathrm{NaCl}$ and stored at room temperature in an atmosphere of high relative humidity ( $\sim 95 \%)$ after 730 days' experimentation.

$\left(C P E-R_{\mathrm{p}}\right)$, in series with the electrolyte resistance $\left(R_{\mathrm{e}}\right)$. The fitting parameters are included in Table II. It can be observed that as the time increases the $R_{\mathrm{p}}$ value decreases. It may be assumed, as an approximation, that the $R_{\mathrm{p}}$ is inversely proportional to the current density at the $E_{\text {corr }}$, also referred as corrosion current density $\left(i_{\text {corr }}\right)$ by means of the Stern-Geary equation: $i_{c o r r}=B / R_{p}$, where $B$ is a constant determined by the Tafel slopes which in the case of steel embedded in concrete takes a value between 26 and $52 \mathrm{mV} /$ decade for the active and passive state, respectively. ${ }^{25}$ The parameter $i_{\text {corr }}$ represents the exchange current density of the corrosion process and is analogous to the rate constant used in chemical kinetics. Based on this consideration, the $i_{\text {corr }}$ reports on the rate of a corrosion process and its evaluation is highly informative. In an attempt to compare the $i_{\text {corr }}$ values obtained in the present research work with the behavior

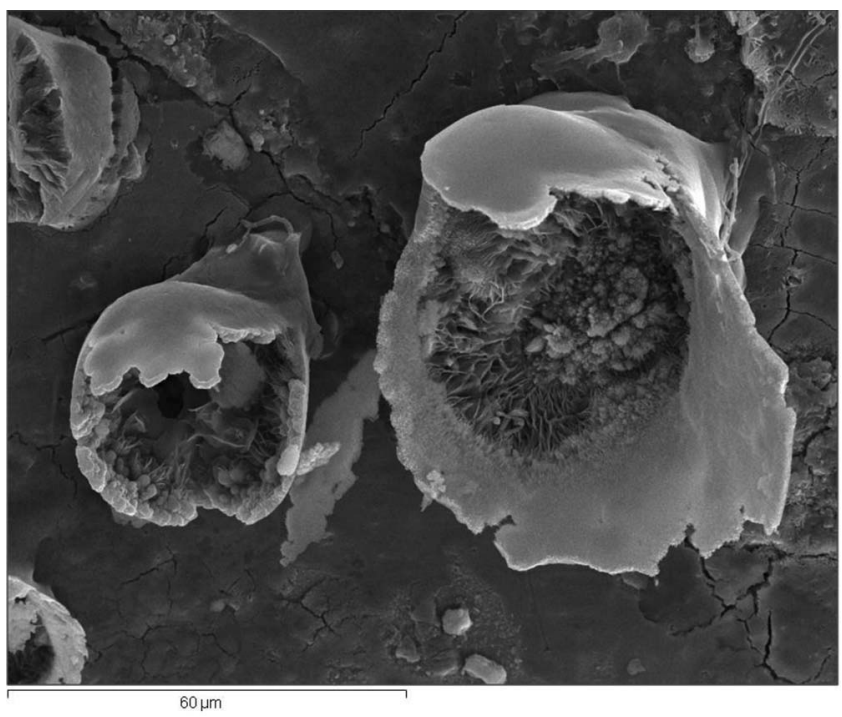

Figure 5. SEM image of carbon steel corrosion products generated at the steel/mortar interface in alkaline activated fly ash mortar polluted with $2 \%$ $\mathrm{NaCl}$ and stored at room temperature in an atmosphere of high relative humidity $(\sim 95 \%)$ after 730 days' experimentation. A geode-like tubular structure partially filled with precipitated minerals can be seen. 

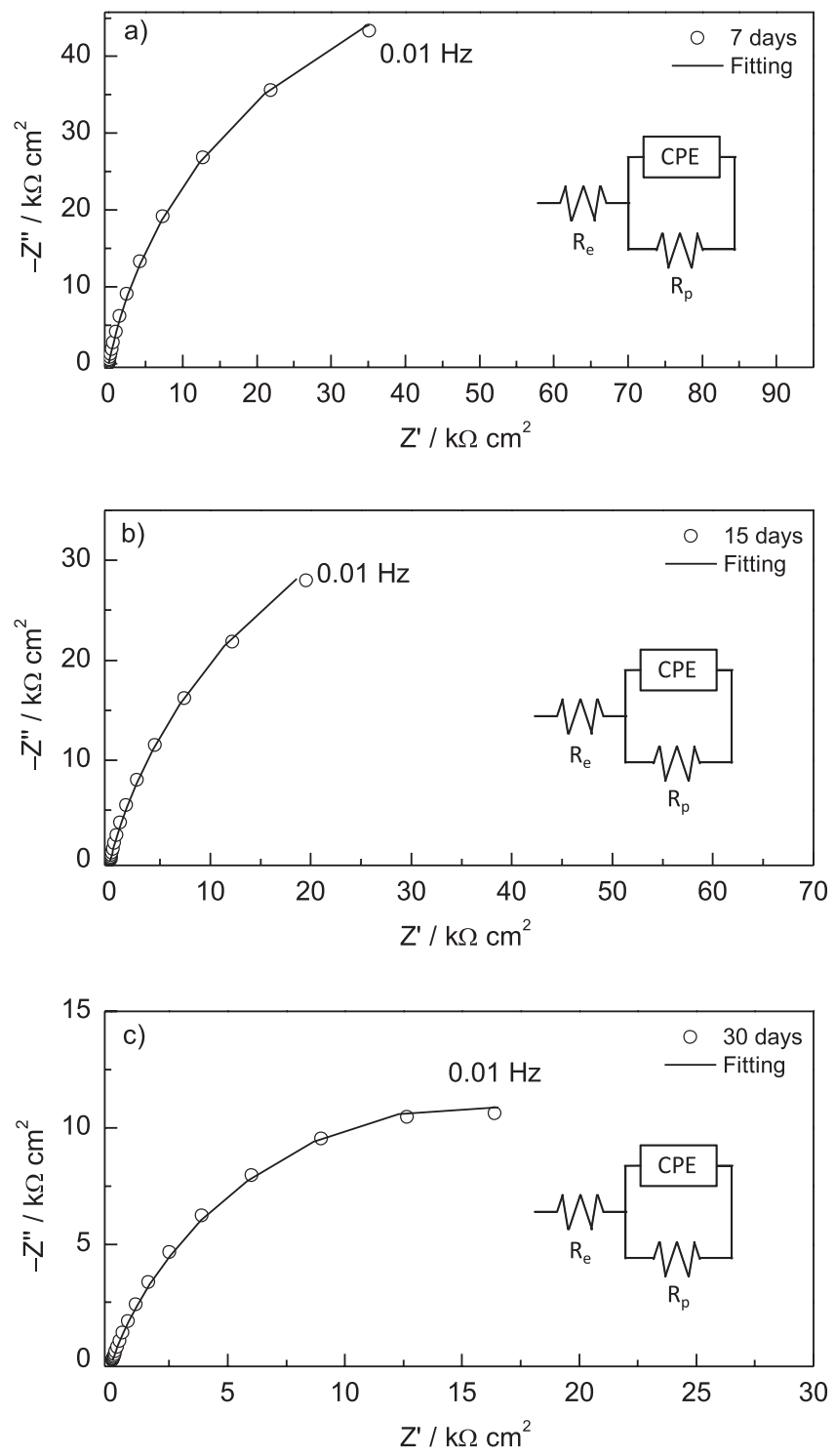

Figure 6. Experimental and simulated Nyquist plots for carbon steel embedded in alkaline activated fly ash mortar polluted with $2 \% \mathrm{NaCl}$ and stored at room temperature in an atmosphere of high relative humidity $(\sim 95 \%)$. The electrical equivalent circuit (EEC) used was constituted by a constant phase element $(C P E)$ in parallel combination with the polarization resistance $\left(R_{\mathrm{p}}\right)$ and in series with the electrolyte resistance $\left(R_{\mathrm{e}}\right)$.

of the traditional OPC mortar/carbon steel system, the Durar Network Specification was used. ${ }^{26}$ This specification indicates that for $\mathrm{i}_{\text {corr }}<0.1 \mu \mathrm{A} / \mathrm{cm}^{2}$ the steel remains in a passive state, for $0.1 \mu \mathrm{A} / \mathrm{cm}^{2}<\mathrm{i}_{\text {corr }}<0.5 \mu \mathrm{A} / \mathrm{cm}^{2}$ the steel undergoes low corrosion, for $0.5 \mu \mathrm{A} / \mathrm{cm}^{2}<\mathrm{i}_{\text {corr }}<1.0 \mu \mathrm{A} / \mathrm{cm}^{2}$ the steel suffers high corrosion, and for $\mathrm{i}_{\text {corr }}>1.0 \mu \mathrm{A} / \mathrm{cm}^{2}$ very high corrosion is exhibited.

Table II. Fitting parameters for carbon steel embedded in alkaline activated fly ash mortar polluted with $2 \% \mathrm{NaCl}$ and stored at room temperature in an atmosphere of high relative humidity $(\sim 95 \%)$. The electrical equivalent circuit used was the inset of Fig. 6.

\begin{tabular}{llllll} 
Time, Days & $R_{\mathrm{e}}, \Omega \mathrm{cm}^{2}$ & $Y_{\mathrm{p}}, \mu \mathrm{S} \mathrm{cm}^{-2} \mathrm{~s}^{\alpha}$ & $\alpha$ & $R_{\mathrm{p}}, \mathrm{k} \Omega \mathrm{cm}^{2}$ & $\chi^{2}$ \\
\hline 7 & 68 & 157 & 0.87 & 120.92 & $3 \times 10^{-3}$ \\
15 & 54 & 175 & 0.84 & 96.98 & $2 \times 10^{-3}$ \\
30 & 79 & 258 & 0.79 & 30.74 & $2 \times 10^{-3}$
\end{tabular}

For 7, 15, and 30 days experimentation the $i_{\text {corr }}$ values were 0.21 , 0.27 and $0.84 \mu \mathrm{A} / \mathrm{cm}^{2}$, respectively, indicating that during the first 15 days the steel electrode underwent a low corrosion process that slightly increased after the first 7 days. After 30 days of experimentation, the steel surface was subjected to a high corrosion process. These results are consistent with the observations made on the $E_{\text {corr }}$, previously discussed.

The CPE unit in Fig. 6 is a distributed electrical element defined by an empirical function of admittance, given by the following expression:

$$
Y=Y_{P}(j \omega)^{\alpha}
$$

where $Y_{\mathrm{p}}$ is a real frequency-independent constant. The dimensionless $\alpha$ exponent is $-1<\alpha<1$ and its physical significance is unclear. ${ }^{27}$ When $\alpha=0$ the $C P E$ unit is a resistor, $R=1 / Y_{\mathrm{p}}$; when $\alpha=1$ it is a capacitor, $C=Y_{\mathrm{p}}$; and when $\alpha=(-1)$ it is an inductor, $L=1 / Y_{\mathrm{p}}$. Finally, if $\alpha=0.5$, Eq. 1 can be written as $\mathrm{Y}=\mathrm{Y}_{P} \sqrt{j \omega}$, and the $C P E$ is the Warburg admittance. ${ }^{28}$ In this case the relationship between the $Y_{\mathrm{P}}$ parameter, Eq. 1, and the Warburg coefficient $\left(\sigma_{\mathrm{W}}\right)$ is given by the expression:

$$
\sigma_{w}=\frac{1}{Y_{P} \sqrt{2}}
$$

The decrease in the $E_{\text {corr }}$ (Fig. 2) and the change in the shape of the Nyquist plots (Fig. 3) may be attributed to a corrosion process at the AAFA mortar/carbon steel interface generating a rust layer on the steel surface. Additionally, the slope of close to $45^{\circ}$ in the low frequency range of the Nyquist plots of Fig. 3 as previously indicated, is a characteristic of a porous electrode, making the use of a transmission line model (TLM) appropriate to interpret the EIS results.

The impedance of a cylindrical pore may be modeled in a simple way using a transmission line containing distributed parameters, so that the impedance is uniformly distributed per unit of length along the pore symmetry axis, see Fig. 7.

The $R_{\mathrm{e}}$ parameter in Fig. 7 is the electrolyte resistance, $Z_{\mathrm{i}}$ is the impedance of the electrode surface around the pore mouth, $Z_{\mathrm{m}}$ is a parameter uniformly distributed along the pore symmetry axis, which models the impedance of the electrode around the pore, and $Z$ is the impedance of the electrode/electrolyte interface along the wall of the pore. It should be noted that the admittance is uniformly distributed per unit of length along the pore. $R_{\mathrm{S}}$ is the electrolyte resistance inside the pore, $Z$ ' is the impedance of the electrode/electrolyte interface at the base of the pore, and finally $Z_{\mathrm{b}}$ is the impedance in the electrode base material. The $R_{\mathrm{e}}$ and $Z_{\mathrm{b}}$ parameters do not directly indicate the impedance of the pore, but have been included in Fig. 7 to complete the EEC.

De Levie studied the frequency response of porous electrodes (cylindrical pores) and rough electrodes (with 'V'-shaped cavities). ${ }^{29}$ The author proposed a model based on the idea that the pores full of electrolyte have a cylindrical shape and that the electrode impedance

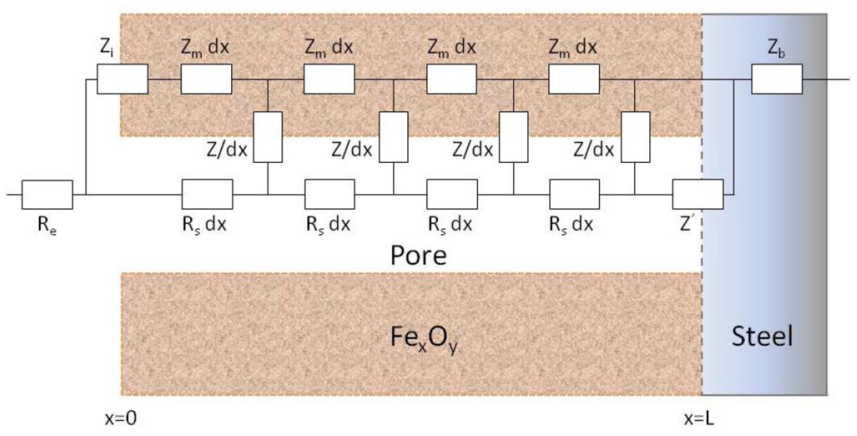

Figure 7. Transmission line as an electrical equivalent circuit (EEC) to model a cylindrical pore. Schematic representation of the inner region $(0<\mathrm{x}<\mathrm{L})$ of a porous electrode consisting of a porous layer generated on the steel. The dashed line suggests the $\mathrm{Fe}_{\mathrm{x}} \mathrm{O}_{\mathrm{y}}$ /liquid interface inside the pores. 
is negligible, $\mathrm{Z}_{\mathrm{m}} \approx 0$. Furthermore, the electrode surface around the pore mouth and the electrode/electrolyte interface at the base of the pore are considered to be insulators, $Z_{\mathrm{i}} \rightarrow \infty$ and $Z^{\prime} \rightarrow \infty$ (see Fig. 7).

The model proposed by de Levie shows that the total impedance of a single one-dimensional pore $\left(Z_{\mathrm{p}}\right)$ of a known length $(L)$ (the pore depth) is given by the following expression:

$$
\mathrm{Z}_{\mathrm{p}}=\left(\sqrt{\mathrm{R}_{\mathrm{s}} \mathrm{Z}_{\mathrm{w}}}\right) \operatorname{coth}\left(\mathrm{L} \sqrt{\frac{\mathrm{R}_{\mathrm{s}}}{\mathrm{Z}_{\mathrm{w}}}}\right)
$$

Raistrick $^{30}$ and Ohmori et al. ${ }^{31}$ used Eq. 3 to calculate the impedance of a porous electrode. The authors assumed that the impedance $(Z)$ of the electrode/electrolyte interface along the pore wall is exclusively capacitive:

$$
Z=\frac{1}{j \omega C}
$$

Park and Macdonald considered that the $Z$ parameter is described by a resistor $\left(R_{\mathrm{w}}\right)$ in parallel combination with a capacitor $\left(C_{\mathrm{w}}\right)$ that model the resistance and capacitance of the electrode/electrolyte interface, respectively, along the pore wall. ${ }^{32}$ These authors considered the impedance of the electrode to be defined by a resistor $\left(Z_{\mathrm{m}} \approx R_{\mathrm{m}}\right)$ and a finite value for the $Z^{\prime}$ parameter. $Z_{\mathrm{p}}$ is given by the following expression:

$$
Z_{p}=\frac{R_{m} R_{s}}{R_{m}+R_{s}} L+\frac{2 R_{m} R_{s} \sqrt{\gamma}+\sqrt{\gamma}\left(R_{m}^{2}+R_{s}^{2}\right) C+S \delta R_{s}^{2}}{\sqrt{\gamma}\left(R_{m}+R_{s}\right)(S \sqrt{\gamma}+\delta C)}
$$

where $\gamma=\frac{R_{m}+R_{s}}{Z}, \delta=\frac{R_{m}+R_{s}}{Z^{\prime}}, C=\cosh (L \sqrt{\gamma})$, and $S=$ $\sinh (L \sqrt{\gamma})$.

It can be observed in Eq. 5 that if the electrode resistance is negligible $\left(R_{\mathrm{m}} \approx 0\right)$ and the electrode/electrolyte interface at the base of the pore is an insulator $\left(Z_{\mathrm{u}} \rightarrow \infty\right)$, the impedance of Eq. 5 coincides with the pore impedance calculated by de Levie, Eq. 3.

It was assumed that the impedance $Z_{\mathrm{w}}$ and $Z_{\mathrm{u}}$ of the electrode/electrolyte interface along the wall and the base of the pore, respectively, was described by a resistor in series with the Warburg impedance $(W)$, both in parallel combination with a capacitor, $\left[\left(R_{\mathrm{w}}+W\right)-C_{\mathrm{w}}\right]$ or $\left[\left(R_{\mathrm{u}}+W\right)-C_{\mathrm{u}}\right]$. The Warburg impedance is defined by the following function: $W=\left(\frac{\sigma_{w}}{\sqrt{j \omega}}\right) \sqrt{2}$. Therefore, the specific impedance of the pore wall is: $Z=\frac{Z_{w}}{2 \pi r L}$, with $Z_{w}=$ $\frac{R_{w}(j \omega)^{2}+\sigma_{w} \sqrt{2}}{2 \omega C_{w}\left(R_{w}(j \omega)^{2}+\sigma_{w} \sqrt{2}\right)}$, and the specific impedance of the base of $(j \omega)^{2}+j \omega C_{w}\left(R_{w}(j \omega)^{2}+\sigma_{w} \sqrt{2}\right)$
the pore is: $Z^{\prime}=\frac{Z_{u}}{\pi r^{2}}$, with $Z_{u}=\frac{R_{u}(j \omega)^{2}+\sigma_{w} \sqrt{2}}{(j \omega)^{2}+j \omega C_{u}\left(R_{u}(j \omega)^{2}+\sigma_{w} \sqrt{2}\right)}$, the average radius of each pore is: $r=\sqrt{\frac{(1-\theta) A}{n \pi}}, \theta$ is the fraction of the total area that is covered with iron oxide $\left(\mathrm{Fe}_{\mathrm{x}} \mathrm{O}_{\mathrm{y}}\right)$, and the area of the sample in the present study is: $A=5.6 \mathrm{~cm}^{2}$.

The total impedance of the electrode $\left(Z_{t}\right)$ is defined by the impedance combination of each pore in parallel, so for $n$ pores $\left(\frac{1}{Z_{t}}=\frac{n}{Z_{p}}\right)$, thus the total impedance is: $Z_{t}=\frac{Z_{p}}{n} \cdot{ }^{33}$

In order to find the impedance of the AAFA mortar/pore/steel system $\left(\mathrm{Z}_{\mathrm{mps}}\right), Z_{\mathrm{t}}$ is assumed to be connected in series with a $C P E-R_{\text {mor }}$ circuit in parallel combination that simulates the AAFA mortar, in series with $R_{\mathrm{e}}$, associated to the electric resistance through the soaked pad used to enable the electrical measurement, see Fig. 8. Thus, $Z_{\mathrm{mps}}$ is defined by the following transfer function:

$$
Z_{m p s}=R_{e}+\frac{R_{m o r}}{1+R_{m o r} Y_{o}(j \omega)^{\alpha}}+Z_{t}
$$

Fig. 8 shows the EEC for the AAFA mortar/pore electrode/carbon steel system. In addition, it includes the $\mathrm{N}-\mathrm{A}-\mathrm{S}-\mathrm{H}$ gel pore network, ${ }^{17,18}$ assuming this structure to be similar to the $\mathrm{C}-\mathrm{S}-\mathrm{H}$ gel for ordinary Portland cement.

Fig. 9 shows the Nyquist plots for a cylindrical pore in AAFA mortar at different experimentation times. Fig. 9 was calculated using Eq. 6, where the $R_{\mathrm{m}}$ and $R_{\mathrm{s}}$ parameters were defined as follows:

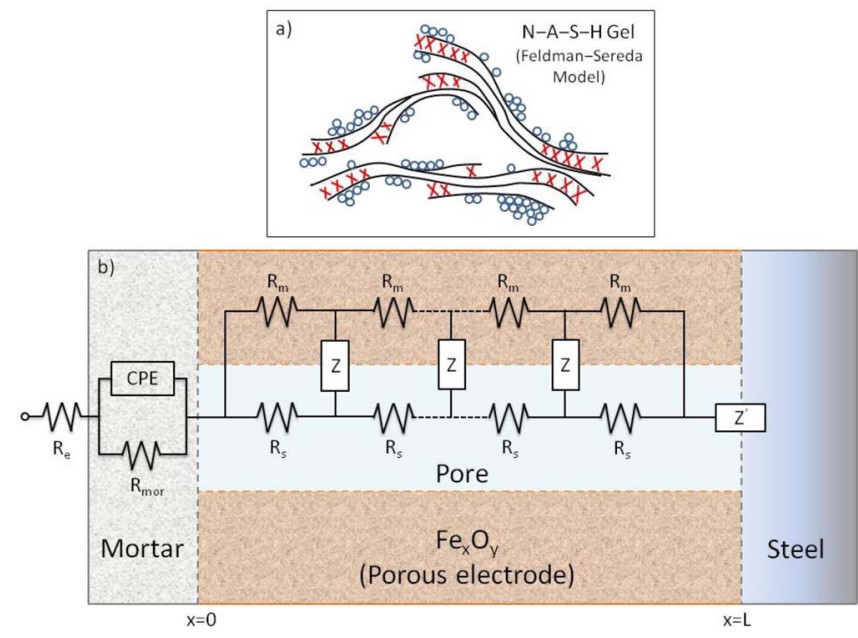

Figure 8. (a) Feldman-Sereda model of the structure of sodium aluminosilicate hydrate $(\mathrm{N}-\mathrm{A}-\mathrm{S}-\mathrm{H})$ gel in alkaline activated fly ash mortar. (b) Transmission line as an electrical equivalent circuit (EEC) to model a cylindrical pore. Schematic representation of the inner region $(0<\mathrm{x}<\mathrm{L})$ of a porous electrode consisting of a porous layer generated on the steel.

$R_{m}=\frac{\rho_{m} n}{\theta A}(\Omega / \mathrm{cm})$ where $\rho_{\mathrm{m}}$ is the resistivity of the oxide, $n$ is the number of pores, $A$ is the area of the sample, $\theta$ is the oxide coverage on the steel surface; and $R_{s}=\frac{\rho_{s} n}{(1-\theta) A}(\Omega / \mathrm{cm})$ where $\rho_{\mathrm{s}}$ is the resistivity of the electrolyte, and the rest of parameters have the same physical meaning. The fitting parameters are included in Table III. The parameters used in the fitting process for 730 days experimentation were: $\rho_{\mathrm{m}}=1100 \Omega \mathrm{cm}, \rho_{\mathrm{s}}=45 \Omega \mathrm{cm}, n=6000$ pores, $\theta=0.90, A=5.6 \mathrm{~cm}^{2}$, and $L=30 \mu \mathrm{m}$. It can be observed that both the $\rho_{\mathrm{m}}$ and $\rho_{\mathrm{s}}$ parameters are distributed per unit of line length,
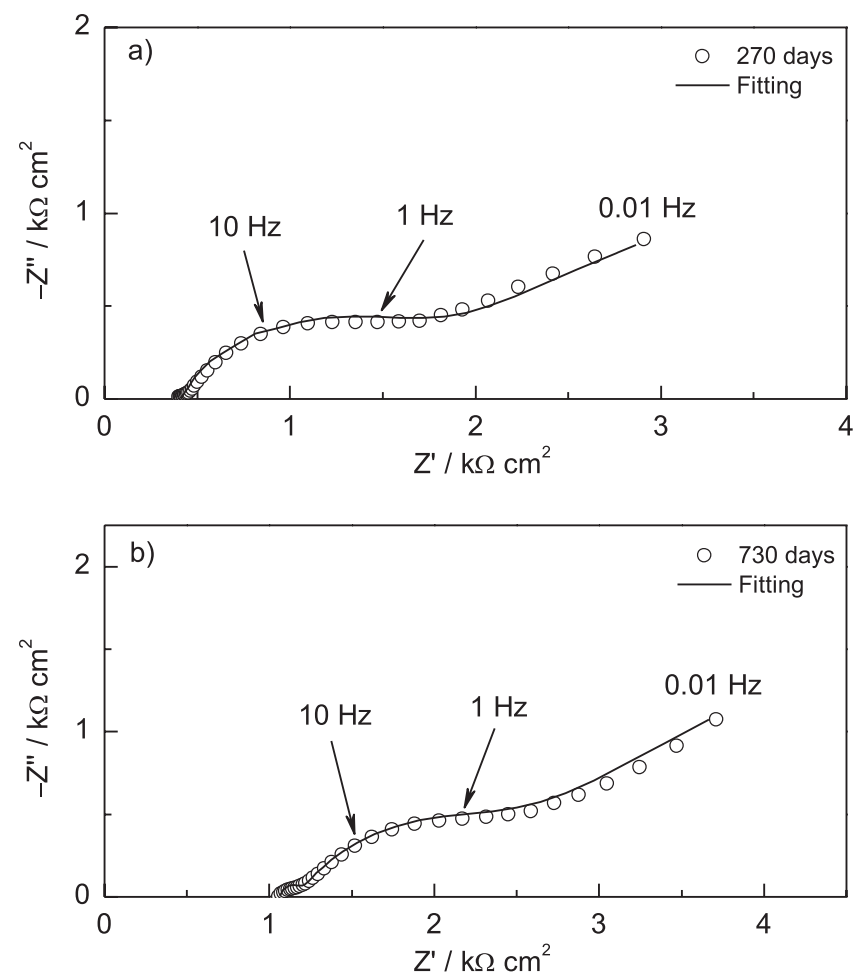

Figure 9. Experimental and simulated Nyquist plots for carbon steel embedded in alkaline activated fly ash mortar polluted with $2 \% \mathrm{NaCl}$ and stored at room temperature in an atmosphere of high relative humidity $(\sim 95 \%)$. The electrical equivalent circuit (EEC) used was the transmission line of Fig. 8. 


\section{Table III. Fitting parameters for carbon steel embedded in alkaline activated fly ash mortar polluted with $2 \%$ NaCl and stored at room temperature} in an atmosphere of high relative humidity $(\sim 95 \%)$. The electrical equivalent circuit used was the transmission line of Fig. 8.

\begin{tabular}{|c|c|c|c|c|c|c|c|c|c|c|c|c|}
\hline Day & $\mathrm{R}_{\mathrm{e}}, \Omega \mathrm{cm}^{2}$ & $\mathrm{R}_{\mathrm{w}}, \mathrm{k} \Omega \mathrm{cm}^{2}$ & $\mathrm{C}_{\mathrm{w}}, \mu \mathrm{Fcm}^{-2}$ & $\mathrm{~L}, \mu \mathrm{m}$ & $\theta$ & $\mathrm{R}_{\mathrm{u}}, \Omega \mathrm{cm}^{2}$ & $\mathrm{C}_{\mathrm{u}}, \mu \mathrm{Fcm}^{-2}$ & $\mathrm{R}_{\mathrm{mor}}, \Omega \mathrm{cm}^{2}$ & $\mathrm{Y}_{\mathrm{mor}}, \mu \mathrm{S} \mathrm{cm} \mathrm{cm}^{-2} \mathrm{~s}^{\alpha}$ & $\alpha$ & $\mathrm{n}$ & $\sigma_{\mathrm{w}}, \Omega \mathrm{cm}^{2} \mathrm{~s}^{-1 / 2}$ \\
\hline 270 & 400 & 10 & 30 & 30 & 0.82 & 20 & 0.2 & 1200 & 190 & 0.64 & 10800 & 55 \\
\hline 730 & 1050 & 10 & 0.8 & 30 & 0.90 & 11 & 0.002 & 1200 & 190 & 0.64 & 6000 & 45 \\
\hline
\end{tabular}

and for this reason the dimensions are $\Omega \mathrm{cm}$. The $Z_{\mathrm{w}}$ and $Z_{\mathrm{u}}$ parameters have been modeled using resistor-capacitor $\left[\left(R_{\mathrm{w}}+W\right)-C_{\mathrm{w}}\right]$ and $\left[\left(R_{\mathrm{u}}+W\right)-C_{\mathrm{u}}\right]$ circuits in parallel combination, respectively, given by $R_{\mathrm{w}}=10 \mathrm{k} \Omega \mathrm{cm}^{2}, C_{\mathrm{w}}=0.8 \mu \mathrm{F} / \mathrm{cm}^{2}, R_{\mathrm{u}}=11 \Omega \mathrm{cm}^{2}$, and $C_{\mathrm{u}}=0.002$ $\mu \mathrm{F} / \mathrm{cm}^{2}, Y_{\text {mor }}=190 \mu \mathrm{S} \mathrm{cm}^{-2} \mathrm{~s}^{\alpha}$, and $\alpha=0.64$. For 270 days were: $\rho_{\mathrm{m}}=1100 \Omega \mathrm{cm}, \rho_{\mathrm{s}}=45 \Omega \mathrm{cm}, n=10800$ pores, $\theta=0.82, A=$ $5.6 \mathrm{~cm}^{2}, L=30 \mu \mathrm{m}, R_{\mathrm{w}}=10 \mathrm{k} \Omega \mathrm{cm}^{2}, C_{\mathrm{w}}=30 \mu \mathrm{F} / \mathrm{cm}^{2}, R_{\mathrm{u}}=20 \Omega$ $\mathrm{cm}^{2}, C_{\mathrm{u}}=0.2 \mu \mathrm{F} / \mathrm{cm}^{2}, Y_{\text {mor }}=190 \mu \mathrm{S} \mathrm{cm}^{-2} \mathrm{~s}^{\alpha}$, and $\alpha=0.64$.

An increase in the $R_{\mathrm{e}}$ value was observed with experimentation time, indicating a loss of conductivity in the electrolyte outside the porous oxide layer formed on the steel surface. Assuming that the resistance to the current flow in the soaked pad is approximately constant for all the impedance measurements, this may be ignored when discussing the variation in $R_{\mathrm{e}}$ over time. The aluminosilicates originally found in the fly ash dissolve, forming a series of ionic species. The smaller species (aluminates and silicates) agglutinate to form larger molecules that precipitate in form of a $\mathrm{N}-\mathrm{A}-\mathrm{S}-\mathrm{H}$ gel. With time the polymerization of this gel continues and the porosity decreases. This fact is most likely responsible for the progressive increase in $R_{\mathrm{e}}$ (see Table III). The small arc defined at high frequency is related to the response of the AAFA mortar, and the parameters used in the EEC were considered constant.

From Table III it can be observed that the number of pores in the rust layer decreased with the experimentation time. It is assumed that as the steel reaches an active dissolution state and the porous film is formed, the pore network gradually starts to become saturated with iron oxides, which are then deposited on the pore wall, thus causing a reduction in the pore diameter. In this way, the fraction of the total area covered with iron oxides $(\theta)$ increased (see Table III).

The value of the oxide resistivity $\left(\rho_{\mathrm{m}}\right)$ is higher than that of the electrolyte resistivity $\left(\rho_{\mathrm{s}}\right)$ because the oxides, as discussed above for Figs. 4 and 5, are less conductive than the electrolyte, which is a basic condition of the model. The pore base resistance $\left(R_{\mathrm{u}}\right)$ was lower than the pore wall resistance $\left(R_{\mathrm{w}}\right)$, favoring the corrosion process at the base of the pore. A small decrease in both resistance values can be observed in Table III, indicating the evolution of the corrosion process over time under an active dissolution state of the steel.

Regarding the capacitances of the pore base and the pore wall, $C_{\mathrm{u}}$ and $C_{\mathrm{w}}$, respectively, it can be observed that $C_{\mathrm{w}}$ presented higher values for both 270 and 730 days of experimentation. These capacitances are associated with the capacitive behavior of the electrochemical double-layer. Adopting the model of a simple parallel plate capacitor, the larger area of the pore wall compared to the pore base explains this difference between $C_{\mathrm{u}}$ and $C_{\mathrm{w}}$ over time. Additionally, it can be observed that both $C_{\mathrm{u}}$ and $C_{\mathrm{w}}$ decreased with the experimentation time, which is in agreement with the reduction in the pore diameter assumed previously. Finally, the arc at intermediate frequencies was related to the response of the pore electrode defining a ("tail") diffusion process at low frequencies.

When using electrochemical techniques, the conversion of electrochemical parameters into weight loss $(m)$ can be achieved by means of Faraday's law: $m=(M / F z) i_{\text {corr }} t$, where $m$ is the weight loss due to corrosion $(\mathrm{g}), M$ is the atomic weight of metal $(55.8 \mathrm{~g} / \mathrm{mol}$ for $\mathrm{Fe}), F$ is the Faraday constant $(96485 \mathrm{C} / \mathrm{mol}), z$ is the ionic charge of metal $(z$ $=2$ for iron: $\mathrm{Fe} \rightarrow \mathrm{Fe}^{2+}+2 \mathrm{e}^{-}$), $i_{\text {corr }}$ is the electrical current (A), and $t$ is the experimentation time (s). For steel, it gives a conversion of 1 $\mu \mathrm{A} / \mathrm{cm}^{2}=11.6 \mu \mathrm{m} /$ year, considering uniform corrosion. According to the $i_{\text {corr }}$ values previously presented, for 7,15 , and 30 days the corrosion rate was $2.49,3.11$, and $9.73 \mu \mathrm{m} /$ year, respectively. Finally, for 270 and 730 days the $i_{\text {corr }}$ values calculated by the application of the
Stern-Geary equation were 2.55 and $2.60 \mu \mathrm{A} / \mathrm{cm}^{2}$ (where $R_{\mathrm{p}}$ was the addition of $R_{\mathrm{w}}$ and $R_{\mathrm{u}}$, and the $B$ constant was $26 \mathrm{mV}$ ), respectively. These $i_{\text {corr }}$ values correspond to a 29.57 and $30.13 \mu \mathrm{m} /$ year corrosion rate for 270 and 730 days, respectively. As can be observed, the corrosion rate of the steel electrode after 270 and 730 days presents very stable values, consistent with the plateau exhibited in Fig. 2. This is probably because at those times of experimentation the access of $\mathrm{O}_{2}$ to the steel constitutes the controlling factor for the corrosion kinetics of the steel electrodes embedded in the mortar specimens. If the $\mathrm{O}_{2}$ reduction were considered the only possible cathodic process (given high $\mathrm{pH}$ in the pore solution and the potential values presented for the electrode at the $E_{\text {corr }}$ (see Fig. 2)), steel corrosion would be controlled for the limiting $\mathrm{O}_{2}$ reduction reaction, which is consistent with the stable $i_{\text {corr }}$ values exhibited by the system.

\section{Conclusions}

The transmission line model (TLM) was applied to describe the evolution of damage to reinforcing steel embedded in alkaline activated fly ash mortar using different interfacial parameters. TLM was used to quantify the parameters that characterize corrosion behavior, such as the resistance of the wall and pore, total oxide coverage, and oxide thickness. Finally, a penetration depth was estimated using impedance data for carbon steel under low corrosion $(\sim 3$ $\mu \mathrm{m} /$ year), high corrosion ( $\sim 10 \mu \mathrm{m} /$ year), and very high corrosion ( $\sim 30 \mu \mathrm{m} /$ year) conditions. The corrosion process was controlled in the long-term by the access of $\mathrm{O}_{2}$ to the porous electrode.

\section{Acknowledgment}

The authors express their gratitude to the Project No. DPI201126480 from the CICYT, Spain, for financial support. M. Criado expresses her gratitude to the Ministry of Science and Innovation and the Spanish Research Council (CSIC) for the Juan de la Cierva (Ref. JCI2010-0783) contract, co-financed by the European Social Fund.

\section{References}

1. J. A. González, Corrosion, 63, 811 (2007)

2. J. P. Broomfield, K. Davies, and K. Hladky, Mater. Performance, 39, 66 (2000)

3. K. Bhargava, A. K. Ghosh, Y. Mori, and S. Ramanujam, Cement Concrete Res., 35, 2203 (2005).

4. K. Tuutti, Swedish Cement and Concrete Research Institute, Stockholm, (1982).

5. K. Suda, S. Misra, and K. Motohashi, Corros. Sci., 35, 1543 (1993).

6. K. K. Aligizaki, M. R. de Rooij, and D. D. Macdonald, Cement Concrete Res., 30, 1941 (2000).

7. O. Poupard, V. L'Hostis, S. Catinaud, and I. Petre-Lazar, Cement Concrete Res., 36, 504 (2006).

8. V. L'Hostis, D. Neff, L. Bellot-Gurlet, and P. Dillmann, Mater. Corros., 60, 93 (2009).

9. S. Ahmad, Cement Concrete Comp., 25, 459 (2003).

10. D. Neff, J. Harnisch, M. Beck, V. L'Hostis, J. Goebbels, and D. Meinel, Mater. Corros., 62, 861 (2011).

11. V. L'Hostis, E. Amblard, W. Guillot, C. Paris, and L. Bellot-Gurlet, Mater. Corros., 64, 185 (2013).

12. G. S. Duffó, W. Morris, I. Raspini, and C. Saragovi, Corros, Sci., 46, 2143 (2004).

13. W.-J. Chitty, P. Dillmann, V. L'Hostis, and C. Lombard, Corros. Sci., 47, 1555 (2005).

14. G. Trabanelli, C. Monticelli, V. Grassi, and A. Frignani, Cement Concrete Res., 35, 1804 (2005).

15. W. Aperador, R. Mejia de Gutiérrez, and D. M. Bastidas, Corros. Sci., 51, 2027 (2009).

16. P. Duxson, A. Fernández-Jiménez, J. L. Provis, G. C. Lukey, A. Palomo, and J. S. J. van Deventer, J. Mater. Sci., 42, 2917 (2007).

17. M. Criado, A. Fernández-Jiménez, and A. Palomo, Micropor. Mesopor. Mater, 106, 180 (2007).

18. M. Criado, A. Fernández-Jiménez, A. G. de la Torre, M. A. G. Aranda, and A. Palomo, Cement Concrete Res., 37, 671 (2007) 
19. D. M. Bastidas, A. Fernández-Jiménez, A. Palomo, and J. A. González, Corros. Sci. 50, 1058 (2008).

20. M. Criado, S. Martínez-Ramírez, S. Fajardo, P. P. Gómez, and J. M. Bastidas, Mater. Corros., 64, 372 (2013).

21. UNE 80-225-93 Spanish Standard. Test method for cements: Chemical analysis. Deterioration of the reactive silica $\left(\mathrm{SiO}_{2}\right)$ content in cements, pozzolans and fly ash (1993).

22. P. Arjuman, M. R. Silbee, and D. M. Roy, in Proc. 10th ICCC, H. Justnes, Editor, 3v 020 4p, Gothenburg, Sweden, (1997).

23. M. Criado, D. M. Bastidas, S. Fajardo, A. Fernández-Jiménez, and J. M. Bastidas, Cement Concrete Comp., 33, 644 (2011).
24. J. Bisquert, Phys. Chem. Chem. Phys., 2, 4185 (2000).

25. S. Feliu, J. A. González, J. M. Miranda, and V. Feliu, Corros. Sci., 47, 217 (2005).

26. Durar Network, Manual de Inspección, Evaluación y Diagnóstico de Corrosión en

Estructuras de Hormigón Armado, CYTED Programe, Rio de Janeiro, 1997.

27. U. Rammelt and G. Reinhard, Electrochim. Acta, 35, 1045 (1990).

28. M. Cai and S.-M. Park, J. Electrochem. Soc., 143, 3895 (1996).

29. R. de Levie, Electrochim. Acta, 8, 751 (1963).

30. I. D. Raistrick, Electrochim. Acta, 35, 1579 (1990).

31. T. Ohmori, T. Kimura, and H. Masuda, J. Electrochem. Soc., 144, 1286 (1997).

32. J. R. Park and D. D. Macdonald, Corros. Sci., 23, 295 (1983).

33. D. M. Bastidas, Corrosion, 63, 515 (2007). 